\title{
Micronutrient supplementation in haemodialysis patients enhances folate levels and reduces homocysteine
}

\author{
M. Hannon-Fletcher ${ }^{1}$, T. Moffitt ${ }^{2}$, A. Molloy ${ }^{3}$ and P. Garrett ${ }^{2}$ \\ ${ }^{1}$ Northern Ireland Centre for Food and Health, University of Ulster, Coleraine, UK, ${ }^{2}$ Western Renal Service, \\ Tyrone County Hospital, Omagh and Altnagelvin Area Hospital, Derry/Londonderry, UK and ${ }^{3}$ The School of Biochemistry \\ and Immunology, Trinity College Dublin, Dublin, Republic of Ireland
}

End stage renal disease is associated with an increase in oxidative stress, cardiovascular disease and cancer. The main treatment for this condition is haemodialysis, which itself induces repetitive bouts of oxidative stress through membrane biocompatibility and endotoxin challenge.

Micronutrient supplementation has been found to have a beneficial effect on oxidative stress levels in haemodialysis patients. However, few long term studies of nutritional supplements containing both folic acid and antioxidant vitamins at physiological and not pharmacological levels have been undertaken.

The aim of this investigation was to examine the effect of a micronutrient supplement (containing folic acid, B vitamins, antioxidant vitamins and trace elements) on folate and homocysteine levels in haemodialysis patients.

Ethical permission was obtained from the Office of Research Ethics Committee Northern Ireland and Governance was obtained from the Wes teen Health and Social Care Trusty. Forty established haemodialysis patients gave informed consent and were then randomised (double blind) to receive daily either a placebo or treatment capsule.

Blood sample were collected and processed at baseline and 12 months to measure homocysteine using an immunoassay ${ }^{(1)}$, plasma folate and whole blood folate were measured by a microbiological assay ${ }^{(2)}$.

37 volunteers completed the intervention one patient died and two had transplants. We report a significant increase in plasma folate $(5.61 \pm 3.6$ vs. $23.39 \pm 9.84 \mathrm{ng} / \mathrm{ml} ; P>0.0001)$ and whole blood folate $(144.04 \pm 80.55$ vs. $341.61 \pm 250.11 \mathrm{ng} / \mathrm{ml} ; P>0.002)$ and a significant reduction in homocysteine $(25.73 . \pm 9.48$ vs. $19.74 \pm 4.3 \mathrm{~mol} / \mathrm{l} ; P>0.05)$, equating to a $31 \%$ reduction.

The significant increase observed in the folate measurements together with the significant reduction in homocysteine support the need for micronutrient supplementation among haemodialysis patients. By lowering homocysteine levels and increasing folate it is proposed that patients will be better protected against cardiovascular complications and the oxidative stress that accompanies their treatment regimes.

1. Leino A (1999) Fully automated measurement of total homocysteine in plasma and serum on the Abbott IMX analyzer. Clin Chem 45, 569-571.

2. Molloy AM \& Scott JM (1997) Microbiological assay for serum, plasma and red cell folate using cryopreserved, microtiter plate method. Methods enzymol 281, 43-53. 